\title{
Seasonal variation in plasma free normetanephrine concentrations: implications for biochemical diagnosis of pheochromocytoma
}

\author{
Christina Pamporaki ${ }^{1}$, Michael Bursztyn ${ }^{1}$, Manja Reimann ${ }^{2}$, Tjalf Ziemssen ${ }^{2}$, \\ Stefan R Bornstein ${ }^{1}$, Fred C G J Sweep ${ }^{3}$, Henri Timmers ${ }^{4}$, Jacques W M Lenders ${ }^{1,4}$ \\ and Graeme Eisenhofer ${ }^{1,5}$ \\ Departments ${ }^{1}$ Medicine III and ${ }^{2}$ Neurology, Center of Clinical Neuroscience, University Hospital Carl Gustav Carus, \\ Technische Universität Dresden, Fetscherstraße 74, D-01307 Dresden, Germany, Departments of ${ }^{3}$ Laboratory \\ Medicine and ${ }^{4}$ Internal Medicine, Radboud University Nijmegen, 6525 GA Nijmegen, The Netherlands and ${ }^{5}$ Institute \\ of Clinical Chemistry and Laboratory Medicine, University Hospital Carl Gustav Carus, Technische Universität \\ Dresden, Fetscherstraße 74, D-01307 Dresden, Germany
}

Correspondence should be addressed to C Pamporaki Email Christina.Pamporaki@ uniklinikum-Dresden.de

\begin{abstract}
Background: Higher plasma concentrations of catecholamines in winter than in summer are established; whether this impacts plasma concentrations of metanephrines used for the diagnosis of pheochromocytoma is unknown. Objective: In this study, we examined seasonal variations in plasma concentrations of metanephrines, the impact of this on diagnostic test performance and the influences of forearm warming ('arterialization' of venous blood) on blood flow and measured concentrations.

Methods: Measurements of plasma concentrations of metanephrines were recorded from 4052 patients tested for pheochromocytoma at two clinical centers. Among these patients, 107 had tumors. An additional 26 volunteers were enrolled for measurements of plasma metanephrines and forearm blood flow before and after forearm warming.

Results: There was no seasonal variation in the plasma concentrations of metanephrines among patients with pheochromocytoma, whereas among those without tumors, plasma concentrations of normetanephrine were higher $(P<0.0001)$ in winter than in summer. Lowest concentrations of normetanephrine were measured in July, with those recorded from December to April being more than $21 \%$ higher $(P<0.0001)$. These differences resulted in a twofold higher $(P=0.0012)$ prevalence of false-positive elevations of normetanephrine concentrations in winter than in summer, associated with a drop in overall diagnostic specificity from $96 \%$ in summer to $92 \%$ in winter $(P=0.0010)$. Forearm warming increased blood flow and lowered $(P=0.0020)$ plasma normetanephrine concentrations.

Conclusions: Plasma concentrations of normetanephrine are subject to seasonal variation with a resulting higher prevalence of false-positive results in winter than in summer. Lowered plasma concentrations of normetanephrine with forearm warming suggest an effect of temperature. These results have implications for considerations of temperature to minimize false-positive results.
\end{abstract}




\section{Introduction}

Higher plasma concentrations of catecholamines in winter than in summer $(1,2)$ are likely linked to the effects of environmental temperature on the sympathetic nervous system (3). Such influences have also been reported to be associated with seasonal variations in blood pressure $(4,5,6)$, possibly contributing to excess cardiovascular morbidity and mortality in winter than in summer $(7,8$, $9,10,11,12,13,14)$. Although seasonal variations in plasma concentrations of catecholamines are well established, it is not clear whether this influences plasma concentrations of normetanephrine and metanephrine, the respective $O$-methylated metabolites of norepinephrine and epinephrine, now used increasingly for the diagnosis of pheochromocytoma (15). If such influences exist, this may result in a seasonal impact on diagnostic test performance.

With the above-mentioned considerations in mind, the present study was carried out to examine seasonal variations in plasma concentrations of normetanephrine and metanephrine and any resulting influence on diagnostic test performance. For this purpose, we evaluated data from 4052 patients who underwent routine testing for pheochromocytoma at two North European tertiary care centers over a 7-year time period. Since plasma normetanephrine and metanephrine exhibit reciprocal higher and lower respective concentrations in forearm venous plasma than in arterial plasma (16), we also examined whether forearm warming ('arterialization') affects changes in the concentrations of the metabolites that might explain any observed seasonal variation.

\section{Subjects and methods}

\section{Subjects}

Subjects included a population of 4052 patients tested under routine clinical care for pheochromocytoma with measurements of plasma free metanephrines at two tertiary clinical care centers: Radboud University Nijmegen Medical Center, Nijmegen, The Netherlands, and the University Hospital of Dresden, Dresden, Germany. The approvals of local ethics committees were obtained for the use of routine patient-derived data, with informed consent being waived subject to anonymity of the source of the data.

A total of 107 patients were determined to have pheochromocytoma, including 55 (29 males and 26 females) from Nijmegen and 52 (22 males and
30 females) from Dresden. There were no differences in gender distributions (58\% females in both Nijmegen and Dresden) or in ages of these patients (median 57 and range 8-89 years for those from Nijmegen; median 57 and range 9-77 years for those from Dresden) at the two centers.

Among patients without pheochromocytoma, there were 1624 (659 males and 965 females) from Nijmegen and 2321 (949 males and 1372 females) from Dresden. There was no difference in gender distributions at the two centers (59\% females in both Nijmegen and Dresden), but patients from Nijmegen (median 53 and range 6-94 years) were younger $(P<0.0010)$ than those from Dresden (median 57 and range 4-96 years).

An additional 26 volunteers (16 hypertensives and ten normotensives) and three patients with adrenal pheochromocytoma were enrolled to examine changes in the plasma concentrations of normetanephrine and metanephrine with forearm warming. The three patients with pheochromocytoma included two with recurrent disease and one with von Hippel-Lindau syndrome. Volunteers had a median age of 53 years (range 39-84) and included 14 females and 12 males. Blood flow was measured in seven volunteers (three hypertensives and four normotensives) before and after forearm warming using laser Doppler flowmetry (LDF). Their median age was 52 years (range 47-61), and these volunteers included three females and four males. All volunteers and patients were enrolled under an approved clinical protocol with written informed consent. All the volunteers underwent a medical history and physical examination to exclude any disease or disorder other than primary hypertension. Volunteers who were taking medications known to increase plasma concentrations of metanephrines (e.g., tricyclic antidepressants) were excluded.

\section{Blood sample collection}

Collection of heparinized blood samples was carried out under routine clinical care with instructions that patients rest supine for at least $30 \mathrm{~min}$ before samples were drawn. The collection of samples was carried out by venipuncture, with instructions that blood samples should be kept on ice until plasma was separated and stored frozen before analyses.

For the 26 volunteers and three patients with pheochromocytoma, blood sampling was carried out 
using an indwelling venous catheter placed in an antebrachial vein of the right forearm at least $30 \mathrm{~min}$ before the first sample was drawn and with the patients remaining supine throughout procedures. Two blood samples were drawn with and without hand and forearm warming using an electric standard heating pad (17), set at a constant temperature of $40{ }^{\circ} \mathrm{C}$, for $30 \mathrm{~min}$. Blood sampling after $30 \mathrm{~min}$ of supine rest with and without the heating pad was carried out in a random order. Blood samples were collected into heparinized tubes and placed on ice until centrifugation $\left(4^{\circ} \mathrm{C}\right)$ to separate the plasma, which was stored at $-80^{\circ} \mathrm{C}$.

\section{Blood flow measurements}

Blood flow was measured in seven volunteers using a PF 5010 Laser Doppler Perimed (Perimed, Järfalla, Sweden), a method largely used to estimate skin perfusion (18). A low-power, 780-mm, solid-state laser beam with a measuring depth of $0.5-1 \mathrm{~mm}$ was used in this system, applied via two small angled thermostatic probes (457), one fixed at the distal part of the inner hand and the other at the median of the inner forearm with the participants lying supine. Relative perfusion was calculated by the concentration and the mean velocity of moving blood cells related to the magnitude of the Doppler signal and the frequency shift $(19,20)$. The LDF perfusion values were measured as relative Laser Doppler Perfusion Units (AU) using the PeriFlux software Stockholm, Sweden.

\section{Laboratory analyses}

In studies involving routine clinical care, measurements of plasma free normetanephrine and metanephrine concentrations were performed using liquid chromatography with electrochemical detection (21). These analyses were carried out according to the same method at Nijmegen and Dresden. As described in detail elsewhere (22), the use of this method yields comparable results at the two centers $(<5 \%$ differences by Bland-Altman plots), but with $4.5 \%$ lower $(P<0.0001)$ concentrations of normetanephrine recorded at Nijmegen than at Dresden. Respective inter-assay coefficients of variation for normetanephrine and metanephrine averaged 4.9 and $5.2 \%$ at Dresden and 4.6 and $7.0 \%$ at Nijmegen. In studies involving forearm warming, all measurements of plasma normetanephrine and metanephrine concentrations were performed using liquid chromatography with tandem mass spectrometry (23).

\section{Statistical analyses}

The JMP statistics software package (SAS Institute, Inc., Cary, NC, USA) was used for statistical analyses. Differences in temperature and plasma concentrations of normetanephrine and metanephrine according to the season or month of sampling and study center were assessed using non-parametric analyses, first using the Kruskal-Wallis test to examine for overall differences between groups and then using the Steel-Dwass method to assess for differences among each of the four seasons or 12 months. Relationships between mean monthly temperature and mean monthly plasma normetanephrine concentrations were examined using Spearman's correlation coefficient $\left(r_{\mathrm{s}}\right)$. Differences between these relationships for Dresden and Nijmegen were examined using stepwise linear regression analysis. Comparisons of plasma metanephrines and blood flow perfusion values with and without the heating stimulus were made using the Wilcoxon signed-rank sum test for paired measurements.

For analyses of seasonal influences on diagnostic specificity and sensitivity, designation of negative and positive results for normetanephrine was according to age-adjusted cut-offs described elsewhere (22) and subsequently used for the routine diagnostic services offered at both Dresden and Nijmegen. These cut-offs are defined by the equation: $\left(\mathrm{UC}_{\mathrm{NMN}}=2.07 \times 10^{-6} \mathrm{age}^{3}+0.540\right)$ for a curvilinear fit of the upper cut-off for normetanephrine $\left(\mathrm{UC}_{\mathrm{NMN}}\right)$ with age from 5 years $\left(\mathrm{UC}_{\mathrm{NMN}}=0.54 \mathrm{nmol} / \mathrm{l}\right)$ up until 65 years $\left(\mathrm{UC}_{\mathrm{NMN}}=1.09 \mathrm{nmol} / \mathrm{l}\right)$. Upper cut-offs from 65 years upwards are then maintained constant at $1.09 \mathrm{nmol} / \mathrm{l}$. For metanephrine, the upper cut-off is set at $0.45 \mathrm{nmol} / 1$. Differences in the proportions of true-negative and false-positive results for plasma metanephrines according to season were assessed according to Fisher's exact test. $P \leq 0.05$ was set as statistically significant.

\section{Results}

\section{Seasonal influences on plasma normetanephrine and metanephrine concentrations}

Plasma concentrations of normetanephrine in patients without pheochromocytoma exhibited highly significant $(P<0.0001)$ overall differences according to both season and month (Fig. 1A). The lowest seasonal concentrations of normetanephrine were observed in summer, with 16 and $13 \%$ higher $(P<0.0001)$ concentrations recorded 

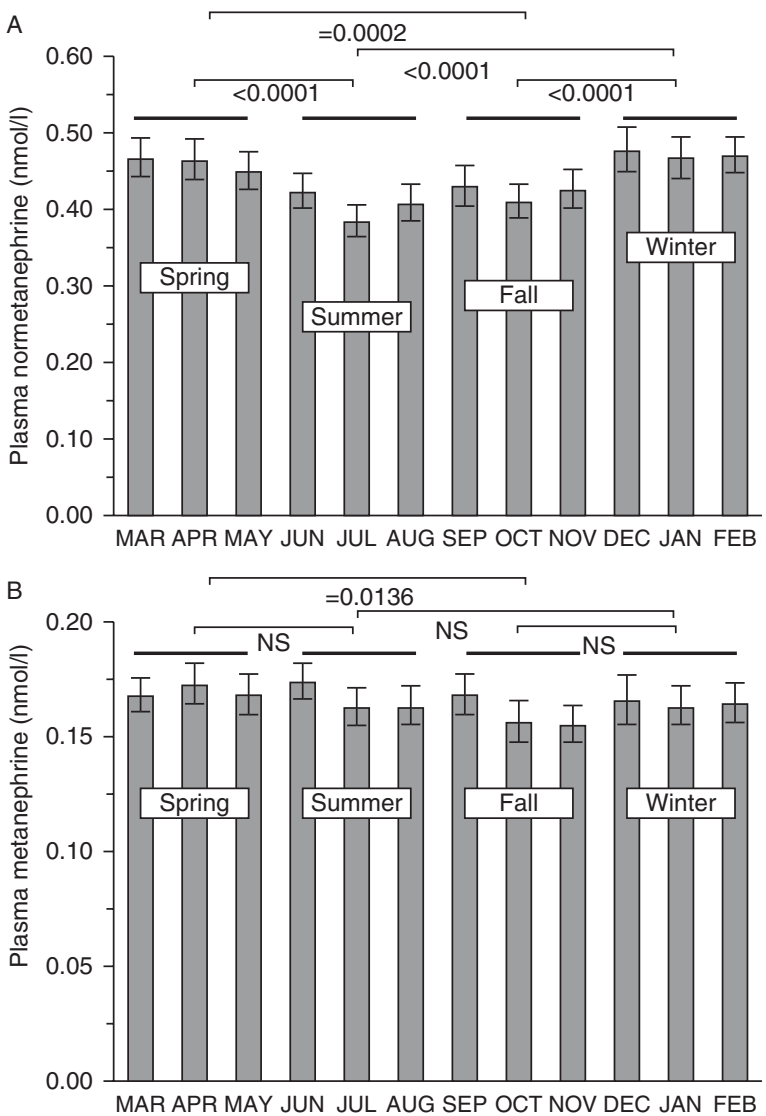

\section{Figure 1}

Seasonal variations in plasma concentrations of normetanephrine (A) and metanephrine (B) in patients without pheochromocytoma.

respectively in winter and spring than in summer. Plasma concentrations of normetanephrine were also respectively 11 and $9 \%$ higher $(P<0.0005$ and $P=0.0002)$ in winter and spring than in fall, whereas those in summer and fall did not differ. The lowest monthly plasma concentrations of normetanephrine were observed in July, with 21-24\% higher $(P<0.0001)$ concentrations recorded from December through to April. In contrast, plasma concentrations of metanephrine exhibited only weak seasonal differences $(P=0.0146)$ with $6 \%$ higher concentrations recorded in spring than in fall $(P=0.0136)$, but no other differences observed between seasons (Fig. 1B).

In contrast to patients without pheochromocytoma, those with tumors exhibited no significant differences in plasma concentrations of normetanephrine or metanephrine according to month or season. In particular, plasma concentrations of normetanephrine in patients with pheochromocytoma did not differ between winter and summer months at either study center (Fig. 2A).

In patients without pheochromocytoma, higher plasma concentrations of normetanephrine in winter than in summer retained significance $(P=0.0001)$ when examined separately for data recorded at both Nijmegen and Dresden (Fig. 2B). However, the magnitudes of summer-to-winter increases in plasma concentrations of normetanephrine were 58\% larger at Dresden than at Nijmegen (19 vs $12 \%)$.

\section{Seasonal differences in plasma normetanephrine concentrations according to center and temperature}

Examination of meteorological records (http://www. weatheronline.co.nz/weather/maps/city 20 July 2013, http://www.wetterkontor.de/de/monatswerte-station.asp, 20 July 2013) indicated lower $(P<0.0001)$ winter than summer temperatures at both Dresden and Nijmegen, with no differences in respective average summer temperatures $\left(17.3\right.$ and $\left.17.0^{\circ} \mathrm{C}\right)$, but lower $(P=0.0148)$ winter temperatures $\left(-0.2\right.$ and $\left.2.0^{\circ} \mathrm{C}\right)$ at Dresden than at Nijmegen (Fig. 2C). Similarly, plasma concentrations of normetanephrine during the summer months did not differ significantly $(P=0.1027)$ between Dresden and Nijmegen; however, during winter months, the concentrations were $16 \%$ higher $(P=0.0008)$ at Dresden than Nijmegen (Fig. 2B).

Using the mean monthly data, significant $(P<0.0050)$ negative relationships between plasma normetanephrine concentrations and temperature were determined for each of the two centers (Fig. 3). Slopes of regression lines describing relationships were similar between the two centers, but plasma concentrations of normetanephrine with respect to temperature were slightly (2.6-4\%) but significantly $(P=0.0420)$ higher at Dresden than Nijmegen.

\section{Seasonal influences on diagnostic test performance}

There were no seasonal differences in diagnostic sensitivity according to age-adjusted upper cut-offs for plasma concentrations of normetanephrine and an upper cut-off of $0.45 \mathrm{nmol} / \mathrm{l}$ for plasma concentrations of metanephrine (Table 1). However, higher plasma concentrations of normetanephrine in winter than summer months among patients without pheochromocytoma were associated with a twofold increase $(P=0.0012)$ in rates of false-positive results from $3.7 \%$ in summer to $7.3 \%$ in winter. In contrast, rates of false-positive results for 

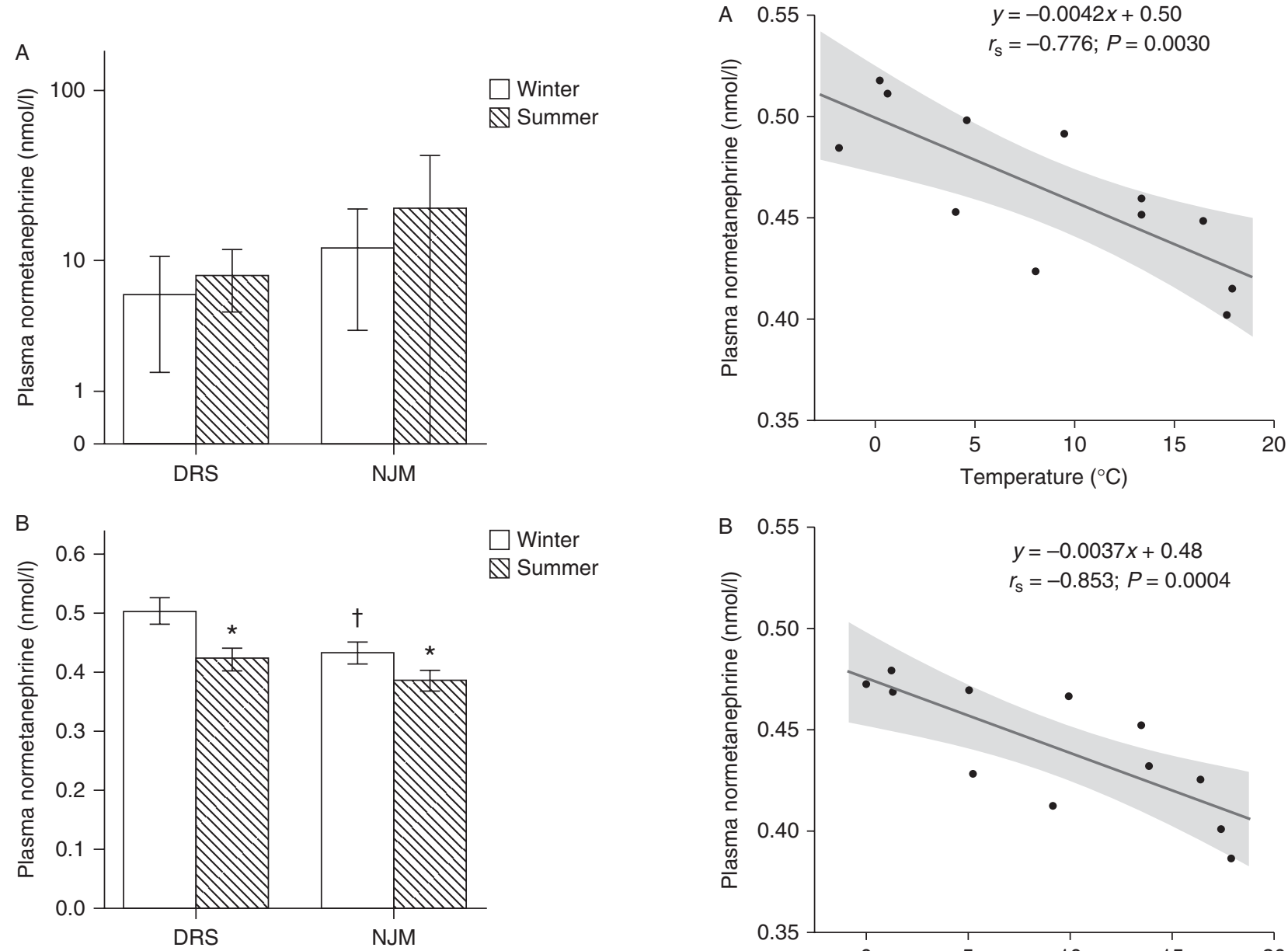

Winter

$\checkmark$ Summer
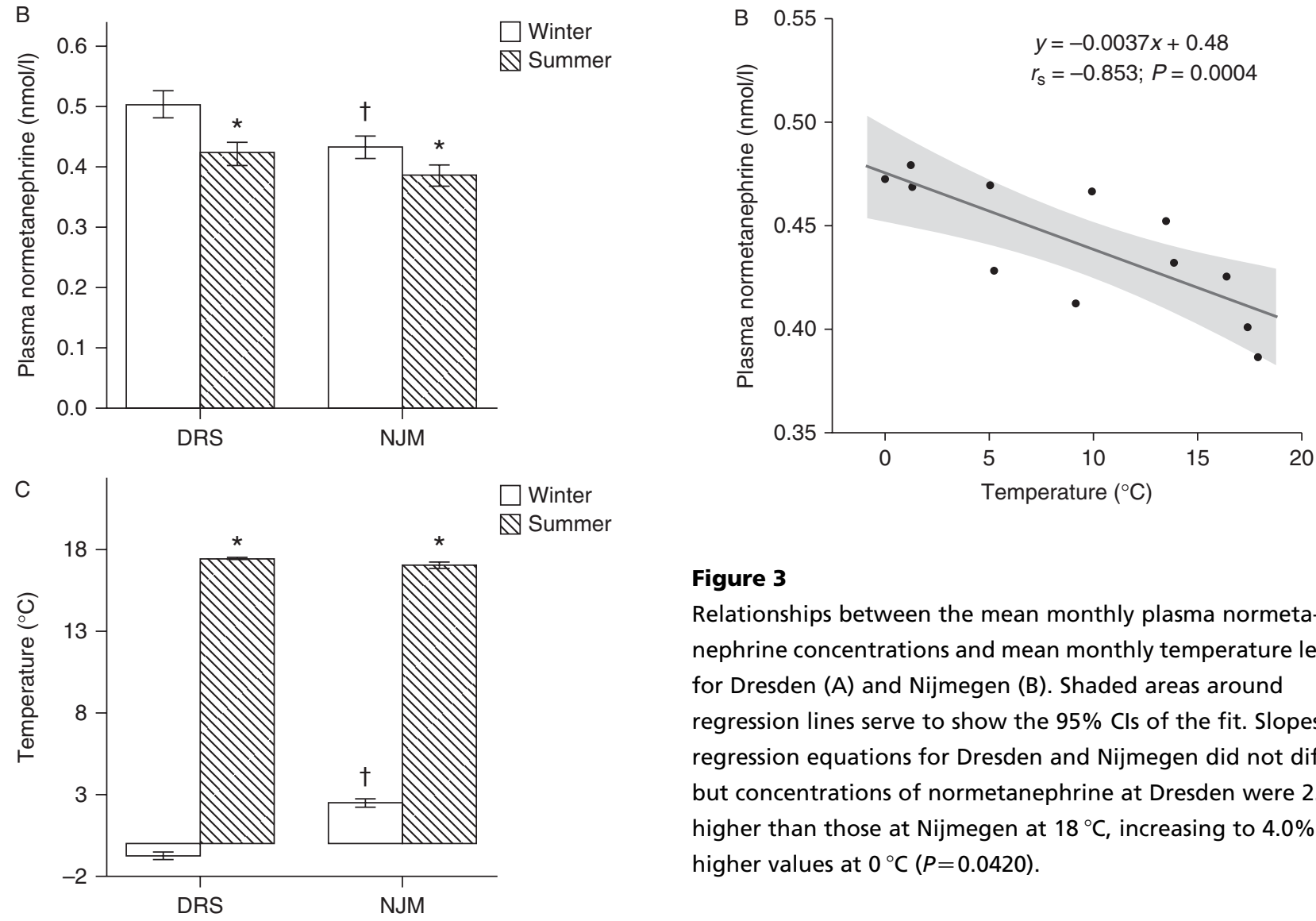

\section{Figure 3}

Relationships between the mean monthly plasma normetanephrine concentrations and mean monthly temperature levels for Dresden (A) and Nijmegen (B). Shaded areas around regression lines serve to show the $95 \% \mathrm{Cls}$ of the fit. Slopes of regression equations for Dresden and Nijmegen did not differ, but concentrations of normetanephrine at Dresden were $2.6 \%$ higher than those at Nijmegen at $18{ }^{\circ} \mathrm{C}$, increasing to $4.0 \%$ higher values at $0{ }^{\circ} \mathrm{C}(P=0.0420)$.

\section{Figure 2}

Plasma concentrations of normetanephrine in patients with (A) and without (B) pheochromocytoma and ambient temperature (C) for winter compared to summer months at Dresden (DRS) compared to Nijmegen (NJM): results are shown as means \pm S.E.M. values. *Different $(P<0.0001)$ summer values compared with winter values. ${ }^{\dagger}$ Different $(P<0.0500)$ values between Dresden and Nijmegen for winter months. 
Table 1 Diagnostic sensitivity and specificity of plasma metanephrines in summer and winter. Values in parentheses indicate numbers of true-positive results (for sensitivity) or truenegative results (for specificity) divided by the total number of results.

\begin{tabular}{|c|c|c|c|}
\hline & Summer & Winter & $P$ value \\
\hline \multicolumn{4}{|l|}{ Sensitivity } \\
\hline NMN & (36/36) 100\% & (22/22) $100 \%$ & 1.0000 \\
\hline $\mathrm{MN}$ & (23/36) 64\% & (13/22) $59 \%$ & 0.7840 \\
\hline $\mathrm{NMN}$ and $\mathrm{MN}$ & (36/36) 100\% & (22/22) 100\% & 1.0000 \\
\hline \multicolumn{4}{|l|}{ Specificity } \\
\hline NMN & (1005/1042) 96\% & (835/896) 93\% & 0.0010 \\
\hline $\mathrm{MN}^{\mathrm{a}}$ & (1031/1036) 99\% & (863/872) 99\% & 0.1850 \\
\hline NMN and MN & (994/1036) 96\% & (806/872) 92\% & 0.0010 \\
\hline
\end{tabular}

NMN, normetanephrine; MN, metanephrine.

${ }^{a}$ For 30 patients, plasma metanephrine concentrations were not measurable.

The summer-to-winter decrease in diagnostic specificity was larger at Dresden than at Nijmegen and only significant $(P=0.0020)$ for Dresden, where the specificity was $95 \%$ in summer and $90 \%$ in winter. At Nijmegen, diagnostic specificity was $98 \%$ in summer and $96 \%$ in winter, a smaller difference compared with that at Dresden.

\section{Forearm warming}

For the 26 normotensive and hypertensive volunteers, plasma concentrations of normetanephrine were lower $(P=0.0020)$ after forearm warming compared to the control period without the heating stimulus (Fig. 4A). No differences were observed for plasma concentrations of metanephrine. The results were similar for the parent catecholamines, with lower $(P=0.0080)$ plasma concentrations of norepinephrine after forearm warming compared to the period without the heating stimulus (Fig. 4B), but with no significant difference in plasma concentrations of epinephrine.

In contrast to the volunteers, none of the three patients with pheochromocytoma exhibited decreased forearm venous plasma concentrations of normetanephrine during local warming of the forearm. In fact, measured concentrations exhibited slight increases with forearm warming from 3.17 to $3.29 \mathrm{nmol} / \mathrm{l}$ in one patient, 0.88 to $1.16 \mathrm{nmol} / \mathrm{l}$ in another, and from 0.78 to $0.82 \mathrm{nmol} / \mathrm{l}$ in the third.

Laser Doppler measurements of relative skin perfusion assessed from the probe fixed at the median inner forearm of seven volunteers exhibited a $234 \%$ increase $(P=0.0180)$ after $30 \mathrm{~min}$ of warming compared to the period without warming (Fig. 5A). This increase in blood flow was associated with an $18 \%(P=0.0180)$ increase in skin temperature (Fig. 5B). Measurements at the distal inner hand similarly showed a $249 \%$ increase $(P=0.0180)$ in blood perfusion after 30 min of forearm warming (Fig. 5C), also associated with a $16 \%$ increase $(P=0.0180)$ in skin temperature (Fig. 5D).

\section{Discussion}

The present study establishing seasonal variations in plasma concentrations of free normetanephrine in patients without pheochromocytoma, with higher concentrations in winter than in summer, are consistent with previous findings of circannual patterns in plasma and urinary norepinephrine concentrations that peak during the winter months (24). This circannual rhythmicity was linked to influences of environmental temperature on the sympathetic nervous system $(25,26)$. In the present study, a link with ambient temperature was similarly indicated by correlations of study center plasma normetanephrine concentrations with regional seasonal temperatures. Most importantly, the data indicate that colder winter months are associated not only with higher plasma normetanephrine concentrations compared with warmer months, but also with increased proportions of false-positive test results and reduced diagnostic specificity in winter than in summer.
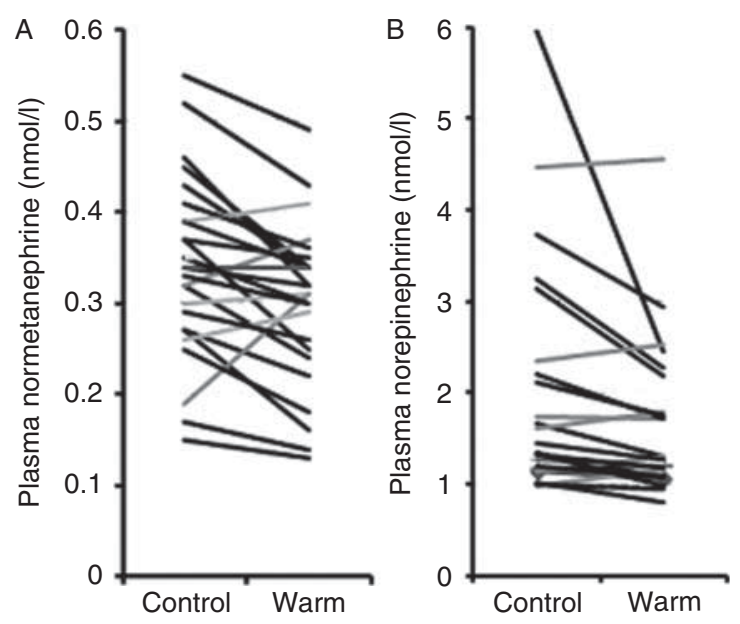

\section{Figure 4}

Differences in plasma normetanephrine (A) and norepinephrine (B) concentrations before and after the application of the heating stimulus. 

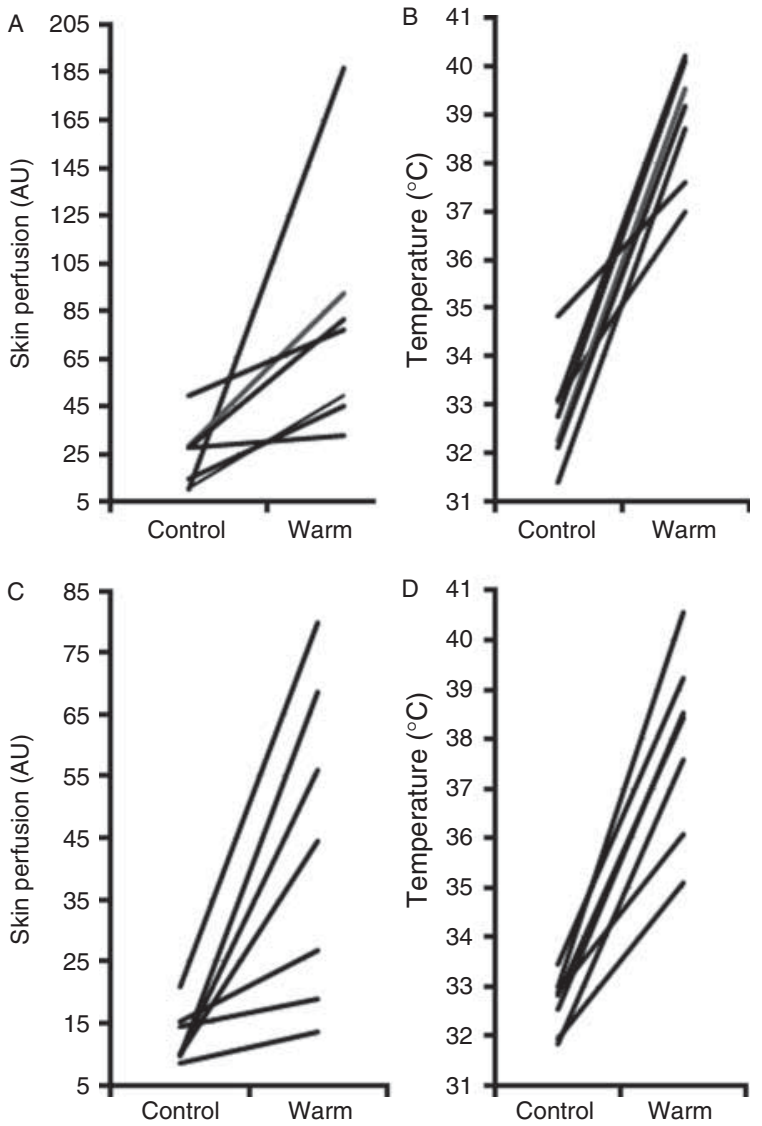

Figure 5

Differences in skin perfusion $(\mathrm{AU})$ and skin temperature $\left({ }^{\circ} \mathrm{C}\right)$ before and after the application of the heating stimulus. Measurements from a probe fixed at the median inner forearm $(A$ and $B$ ) and at the distal inner hand $(C$ and $D$ ) respectively.

Although a cold-induced generalized increase in sympathetic outflow presumably contributes to higher winter plasma concentrations of norepinephrine and normetanephrine, our findings that localized warming of the arm decreases the concentrations of both amines indicate contributions of additional factors. These include vasoconstriction- and vasodilation-associated changes in local sympathoneural norepinephrine release and forearm blood flow, influencing the dynamics of local clearance processes (27). More specifically, studies of norepinephrine kinetics have established that forearm venous plasma concentrations of norepinephrine reflect contributions from locally and systemically released transmitter, both influenced by changes in local blood flow $(27,28,29,30)$. While vasoconstriction leads to substantially increased local extraction of norepinephrine from the arterial inflow, it is also associated with increased local release of norepinephrine and a vasoconstrictionassociated reduction in the volume of blood in the forearm venous outflow into which the escaping norepinephrine is diluted. The end result is a larger arterial-to-venous increase in plasma concentrations of norepinephrine associated with vasoconstriction than with vasodilation and increased blood flow.

Similar to the plasma concentrations of norepinephrine, those of free normetanephrine are also higher in the outflowing venous blood than in the inflowing arterial blood (16), reflecting production of the metabolite from locally released norepinephrine. Thus, the decreases in forearm venous plasma concentrations of normetanephrine with local warming observed in this study reflect both reduction in norepinephrine released by local sympathetic nerves and the associated increase in blood flow, which acts further to dilute the normetanephrine produced from the local metabolism of norepinephrine. Since metanephrine is mainly derived from adrenal medullary sources rather than from systemic or local forearm metabolism, this metabolite of epinephrine does not exhibit decreases in forearm venous concentrations with local warming. This and the relative independence of metanephrine production from changes in sympathoadrenal activity may explain why only normetanephrine and not metanephrine exhibits seasonal variations and decreases in forearm venous plasma concentrations with local warming.

In support of the above-mentioned notion, none of the three patients with pheochromocytoma showed decreases in the plasma concentrations of normetanephrine with forearm warming; in fact, all exhibited slight increases in plasma concentrations of normetanephrine, an effect expected to result from decreased local extraction of the metabolite consequent to increased blood flow.

The above-mentioned findings suggest that attention to the temperature of blood sampling might not only reverse the increased rates of false-positive results, and lowered diagnostic specificity for tests of plasma metanephrine during colder than warmer seasons, but might also improve diagnostic sensitivity. Since false-positive results are far more prevalent for plasma normetanephrine than for metanephrine and because normetanephrine is the more important metabolite for diagnosis of pheochromocytoma, improved diagnostic performance might also be expected with blood samples collected under conditions of forearm warming.

A minor limitation of this study was that the data were derived from single patient samples and not from multiple 
samples collected from the same patients at different seasonal time points. Although a within-subjects design may offer improved statistical power than betweensubjects comparisons, such an approach is not practical for evaluations of routine clinical data from which impact on diagnostic test performance is most appropriately established. The between-subjects comparisons of the present study involving over 4000 patients not only provided sufficient power to document seasonal influences on plasma concentrations of normetanephrine at two separate centers, but also provided sufficient data to establish the impact on diagnostic test performance under conditions of routine clinical care. Most importantly, although the winter-to-summer 16\% difference in plasma concentrations of normetanephrine is relatively minor compared with a recently described 50\% difference in seated to supine sampling plasma concentrations (31), this relatively small difference is sufficient to result in a twofold increase in false-positive test results in winter than in summer. This influence further illustrates the importance of considering preanalytical factors when performing measurements of plasma metanephrines as a test for the diagnosis of pheochromocytoma.

In summary, plasma concentrations of normetanephrine are subject to seasonal variation with a resulting higher prevalence of false-positive results in winter than in summer. Lowered plasma concentrations of normetanephrine with forearm warming suggest an effect of temperature possibly related to reduced systemic and local forearm release of norepinephrine and vasodilationinduced dilution of venous concentrations of normetanephrine. These results have implications for considerations of temperature to minimize false-positive results during the diagnostic work-up of patients with suspected pheochromocytoma.

\section{Declaration of interest}

The authors declare that there is no conflict of interest that could be perceived as prejudicing the impartiality of the research reported.

\section{Funding}

This work was supported by the Deutsche Forschungsgesellschaft (El855/1-1).

\section{References}

1 Radke KJ \& Izzo JL. Seasonal variation in haemodynamics and blood pressure-regulating hormones. Journal of Human Hypertension 201024 410-416. (doi:10.1038/jhh.2009.75)
2 Kruse HJ, Wieczorek I, Hecker H, Creutzig A \& Schellong SM. Seasonal variation of endothelin-1, angiotensin II, and plasma catecholamines and their relation to outside temperature. Journal of Laboratory and Clinical Medicine 2002140 236-241. (doi:10.1067/mlc.2002.127169)

3 Hiramatsu K, Yamada T \& Katakura M. Acute effects of cold on blood pressure, renin angiotensin-aldosterone system, catecholamines and adrenal steroids in man. Clinical and Experimental Pharmacology and Physiology 198411 171-179. (doi:10.1111/j.1440-1681.1984.tb00254.x)

4 Rose G. Seasonal variation in blood pressure in man. Nature 1961189 235. (doi:10.1038/189235a0)

5 Cuspidi C, Ochoa JE \& Parati G. Seasonal variation of blood pressure: a complex phenomenon. Journal of Hypertension 201230 1315-1320. (doi:10.1097/HJH.0b013e328355d7f9)

6 Modesti PA, Morabito M, Masseti L, Rapi S, Orlandini S, Mancia G, Gansini GF \& Parati G. Seasonal blood pressure changes: an independent relationship with temperature and daylight hours. Hypertension 201361 908-914. (doi:10.1161/HYPERTENSIONAHA. 111.00315)

7 Healy JD. Excess winter mortality in Europe: a cross country analysis identifying key risk factors. Journal of Epidemiology and Community Health 200357 784-789. (doi:10.1136/jech.57.10.784)

8 Turner LR, Barnett AG, Connell D \& Tong S. Ambient temperature and cardiorespiratory morbidity: a systematic review and meta-analysis. Epidemiology 201223 594-606. (doi:10.1097/EDE.0b013e3182572795)

9 Wilkinson P, Pattenden S, Armstrong B, Fletcher A, Kovats RS, Mangtani P \& McMichael AJ. Vulnerability to winter mortality in elderly people in Britain: population based study. British Medical Journal 200418 329-647. (doi:10.1136/bmj.38167.589907.55)

10 Pell JP, Sirel J, Marsden AK \& Cobbe SM. Seasonal variation in out of hospital cardiopulmonary arrest. Heart 199982 680-683. (doi:10.1136/hrt.826.680)

11 Vrbova L, Crighton EJ, Mamdani M, Moineddin R \& Upshur RE. Temporal analysis of acute myocardial infarction in Ontario, Canada. Canadian Journal of Cardiology 200521 841-845.

12 Nakanishi N, Nishizawa S, Kitamura Y, Nakamura T, Matsumuro A, Sawada T \& Matsubara H. Circadian weekly and seasonal mortality variations in out-of-hospital cardiac arrest in Japan: analysis from AMIKyoto Multicenter Risk Study database. American Journal of Emergency Medicine 201129 1037-1043. (doi:10.1016/j.ajem.2010.06.018)

13 Myint PK, Vowler SL, Woodhouse PR, Redmayne O \& Fulcher RA. Winter excess in hospital admissions, in-patient mortality and length of acute hospital stay in stroke: a hospital database study over six seasonal years in Nirfolk, UK. Neuroepidemiology 200728 79-85. (doi:10.1159/000098550)

14 McGuinn L, Hajat S, Wilkinson P, Armstrong B, Anderson HR, Monk V $\&$ Harrison R. Ambient temperature and activation of implantable cardioverter defibrillators. International Journal of Biometeorology 2013 57 655-662. (doi:10.1007/s00484-012-0591-1)

15 Lenders JW, Eisenhofer G, Mannelli M \& Pacak K. Pheochromocytoma. Lancet 2005366 665-675. (doi:10.1016/S0140-6736(05)67139-5)

16 Eisenhofer G, Rundquist B, Aneman A, Friberg P, Dakak N, Kopin IJ, Jacobs MC \& Lenders JW. Regional release and removal of catecholamines and extraneuronal metabolism to metanephrines. Journal of Clinical Endocrinology and Metabolism 199510 3009-3017. (doi:10.1210/jc.80.10.3009)

17 Jackson RA, Peters M, Advani V, Perry G, Rogers J, Brough WH \& Pilkington TR. Forearm glucose uptake during the oral glucose tolerance test in normal subjects. Diabetes 197322 442-458. (doi:10.2337/diab.22.6.442)

18 Figueiras E, Roustit M, Semedo S, Ferreira LF, Crascowski JL \& Humeau A. Sample entropy of laser Doppler flowmetry signals increases in patients with systemic sclerosis. Microvascular Research 201182 152-155. (doi:10.1016/j.mvr.2011.05.007)

19 Klonizakis M, Yeung JM, Lingam K, Nash JR, Manning G \& Donnelly R. Contrasting effects of varicose vein surgery on endothelial-dependent and -independent cutaneous vasodilation in the perimalleolar region. 
European Journal of Vascular and Endovascular Surgery 200631 434-438. (doi:10.1016/j.ejvs.2005.10.017)

20 Humeau A, Steenbergen W, Nilsson H \& Strömberg T. Laser Doppler perfusion monitoring and imaging: novel approaches. Medical and Biological Engineering and Computing 200745 421-435. (doi:10.1007/ s11517-007-0170-5)

21 Lenders JW, Eisenhofer G, Armando I, Keiser HR, Goldstein DS \& Kopin IJ. Determination of metanephrines in plasma by liquid chromatography with electrochemical detection. Clinical Chemistry 199339 97-103.

22 Eisenhofer G, Lattke P, Herberg M, Siegert G, Qin N, Därr R, Hoyer J, Villinger A, Prejbisz A, Januszewicz A et al. Reference intervals for plasma free metanephrines with an age adjustment for normetanephrine for optimized laboratory testing of pheochromocytoma. Annals of Clinical Biochemistry 201350 62-69. (doi:10.1258/acb.2012. 012066)

23 Peitzsch M, Prejbisz A, Kroiss M, Beuschlein F, Arlt W, Siegert G \& Eisenhofer G. Analysis of plasma 3-methoxytyramine, normetanephrine and metanephrine by ultraperformance liquid chromatography-tandem mass spectrometry: utility for diagnosis of dopamine-producing metastatic phaeochromocytoma. Annals of Clinical Biochemistry 201350 147-155. (doi:10.1258/acb.2012.012112)

24 Nicolau GY, Haus E, Bogdan C, Plinga L, Robu E, Ungureanu E, Sackett-Lundeen L \& Petrescu E. Circannual rhythms of systolic and diastolic blood pressure in relation to plasma aldosterone and urinary norepinephrine in elderly subjects and in children. Endocrinology 1986 24 97-107.

25 Izzo JL Jr, Larrabee PS, Sander E \& Lillis LM. Hemodynamics of seasonal adaptation. American Journal of Hypertension 19903 405-407. (doi:10.1093/ajh/3.5.405)

26 Rowell LB. Human cardiovascular adjustments to exercise and thermal stress. Physiological Reviews $1974 \mathbf{5 4} 75-159$.

27 Eisenhofer G. Sympathetic nerve function-assessment by radioisotope dilution analysis. Clinical Autonomic Research 2005154 264-283. (doi:10.1007/s10286-005-0292-5)

28 Goldstein DS, Eisenhofer G, Sax FL, Keiser HR \& Kopin IJ. Plasma norepinephrine pharmacokinetics during mental challenge. Psychosomatic Medicine 198749 591-605.

29 Best JD \& Halter JB. Release and clearance rates of epinephrine in man: importance of arterial measurements. Journal of Clinical Endocrinology and Metabolism 198255 263-268. (doi:10.1210/jcem-55-2-263)

30 Marker JC, Cryer PE \& Clutter WE. Simplified measurement of norepinephrine kinetics: application to studies of aging and exercise training. American Journal of Physiology 1994267 380-387.

31 Daerr R, Pamporaki C, Peitzsch M, Miehle K, Prejbisz A, Peczkowska M, Weismann D, Beuschlein F, Sinnott R, Bornstein SR et al. Biochemical diagnosis of phaeochromocytoma using plasma-free normetanephrine, metanephrine and methoxytyramine: importance of supine sampling under fasting conditions. Clinical Endocrinology (oxf), 2013. (doi:10.1111/cem.12327)

Received 16 August 2013

Revised version received 13 November 2013

Accepted 28 November 2013 